This item was submitted to Loughborough's Research Repository by the author.

Items in Figshare are protected by copyright, with all rights reserved, unless otherwise indicated.

\title{
Pacifying Babel's Tower: A scientometric analysis of polycentricity in urban research
}

PLEASE CITE THE PUBLISHED VERSION

https://doi.org/10.1177/0042098015573455

\section{PUBLISHER}

SAGE Publications @ Urban Studies Journal Limited

VERSION

AM (Accepted Manuscript)

\section{PUBLISHER STATEMENT}

This work is made available according to the conditions of the Creative Commons Attribution-NonCommercialNoDerivatives 4.0 International (CC BY-NC-ND 4.0) licence. Full details of this licence are available at: https://creativecommons.org/licenses/by-nc-nd/4.0/

\section{LICENCE}

CC BY-NC-ND 4.0

\section{REPOSITORY RECORD}

Van Meeteren, Michiel, Ate Poorthuis, Ben Derudder, and Frank Witlox. 2019. "Pacifying Babel's Tower: A Scientometric Analysis of Polycentricity in Urban Research". figshare. https://hdl.handle.net/2134/37045. 


\section{Pacifying Babel's Tower: A scientometric analysis of polycentricity in urban research}

Van Meeteren M, Poorthuis A, Derudder B and Witlox F (2016) Pacifying Babel's Tower: A scientometric analysis of polycentricity in urban research. Urban Studies 53(6), 12781298.

Please refer to the published version.

\section{Abstract}

It is sometimes claimed that the degree of polycentricity of an urban region influences that region's competitiveness. However, because of widespread use and policy relevance, the underlying concept of polycentricity has become a 'stretched concept' in urban studies. As a result, academic debate on the topic leads to situations reminiscent of Babel's Tower. This meta-study of the scientific literature in urban studies traces the conceptual stretching of polycentricity using scientometric methods and content analysis. All published studies that either apply the concept directly or cite a work that does, were collected from the Scopus bibliographic database. This resulted in a citation network with over 9,000 works and more than 20,000 citations between them. Network analysis and clustering algorithms were used to define the most influential papers in different citation clusters within the network. Subsequently, we employed content analysis to systematically assess the mechanisms associated with the formation of polycentric urban systems in each of these papers. Based on this meta-analysis, we argue that the common categorization of polycentricity research in intra-urban, inter-urban and inter-regional polycentricity is somewhat misleading. More apt categorizations to understand the origins of polycentricity's conceptual ambiguity relate to different methodological traditions and geographical contexts in which the research is conducted. Nonetheless, we observe a firm relation across clusters between assessments of polycentricity and different kinds of agglomeration economies. We conclude by proposing a re-conceptualisation of polycentricity based on explicitly acknowledging the variable spatial impact of these different kinds of agglomeration economies. 


\subsection{Introduction}

In their most recent collaborative step regarding spatial policy, the Territorial Agenda 2020 (CEC, 2011), the European Union ministers of spatial planning stress that:

Polycentric and balanced territorial development of the EU is key element of achieving territorial cohesion [sic]. Where the most developed cities and regions within Europe cooperate as parts of a polycentric pattern they add value and act as centers contributing to the development of their wider regions. Urban development policies also have a significant role in this regard. Polycentric territorial development policy should foster the territorial competitiveness of the EU territory also outside the core 'Pentagon area'.

Commision of the European Communities (CEC, 2011: 7)

This quote is illustrative of the large causal power that EU governments attribute to the polycentric spatial structure of urban systems, in this case to achieve 'territorial competitiveness' and 'territorial cohesion'. The discussion on the relation between urban form and competitiveness is particularly articulated in Europe, but extends to urban studies worldwide (Hall and Pain, 2006). Meanwhile, most recent academic research that discusses the underlying concept of polycentricity ${ }^{1}$ has stressed its fuzziness and polyvalence (Cattan, 2007; Green, 2007; Lambregts, 2009; Burger and Meijers, 2012; Vasanen, 2012): the term means different things at different scales and to different authors, and over the years the concept has become 'stretched' (Sartori, 1970).

Conceptual stretching is particularly problematic when large causal claims are invoked, because any discussion on a concept's utility for either policy or scientific analysis drowns in Babylonian misunderstandings (Sartori, 2009 [1975]; cf. Markusen, 1999). According to Davoudi (2007), the ambiguity of the polycentricity concept in planning circles has even been instrumentalized: as every actor involved in a political process can attribute their own interpretation to it, it becomes easier to (seemingly) establish consensus. Although such instrumentalism might be practical in the politically charged situations associated with spatial planning, this situation is detrimental for scientific communication and theory development. How can we establish an academic debate on whether polycentric urban systems enhance economic competitiveness if we do not even have consensus on what a polycentric urban system is?

According to previous literature reviews on the topic (e.g. Kloosterman and Musterd, 2001; Davoudi, 2003; Green, 2007; Burger and Meijers, 2012), academic debate on polycentricity in urban studies has revolved along two broad axes: those of i) scale; and ii)

\footnotetext{
${ }^{1}$ Vandermotten et al. (2008: 1207) suggest distinguishing between polycentricity as an analytical concept and polycentrism as a normative planning concept. Although this distinction is useful, it has so far not been consistently applied in the literature. Instead, it was found that the terms were generally regarded synonyms.
} 
functionality versus morphology. First, Davoudi (2003) discerns different scaledependent connotations of the concept: intra-urban, inter-urban and inter-regional polycentricity, which all have different meanings and originate in different scholarly debates in urban studies and planning. Second, polycentric urban systems are sometimes analyzed based on morphological aspects and rank-size distributions (e.g. Batty, 2001). However, according to Green (2007) and Burger and Meijers (2012), a morphological polycentric urban system does not necessarily imply that the urban system also functions as such. In their research, they therefore utilize flow data to measure the similarities and differences between morphological and functional polycentricity. Recently, both Burger and Meijers (2012) and Vasanen (2012) have tried to overcome the empirical ambiguities of the concept flowing from these two axes of debate. Although their contributions resolve important research problems, it remains unclear whether a single univocal definition of polycentricity will emerge as a result.

Against this backdrop, the purpose of this meta-study is to understand the full connotative variety of polycentricity in the academic literature in urban studies and explore pathways to alleviate conceptual stretching. This implies providing tentative answers to the following questions: What authors in urban studies employ the concept of polycentricity? What definitions do they utilize? To what extent can we discern the axes of debate that are identified in other literature reviews (i.e. issues of scale and functional versus morphological polycentricity) as well in scientometric citation patterns? And lastly, what is the potential of bridging conceptual differences by proposing a unified abstract concept? This paper seeks to address these questions using a two-tiered, multi-method approach. First, we utilize a range of scientometric methods to create a quantitative 'bird's eye view' of the literature on polycentricity in urban studies. This is followed by a discussion on the possibilities of scientometric analysis for understanding concept formation. The subsequent section discusses the scientometric methods followed by a presentation of the scientometric findings. This results in a 'map' of the polycentricity literature in which the scale debate is clearly recognizable between the subclusters. The second tier of the research, a qualitative content analysis, deepens the analysis and provides insight on the degree of conceptual stretching within and between the intra-urban and inter-urban clusters of polycentricity research. The analysis reveals that the debates regarding polycentricity are implicitly but thoroughly intertwined with debates regarding the spatial scale of agglomeration economies. The concluding section discusses how scientometric methods can help alleviate problems of conceptual stretching, assesses the results and reflects upon to what extent the concept of polycentricity can be 'de-stretched'.

\subsection{Conceptual stretching and scientometrics}

\section{Polycentricity as a stretched concept}

Conceptual stretching occurs because the number of properties ascribed to a concept (the intension) and the number of situations a concept applies to (the extension) expand simultaneously when research is replicated in different contexts and by different authors 
(Sartori, 1970). Conceptual stretching is therefore quite often the result of a concept's success. All contributors to a debate emphasize different aspects, use different indicators or methods, and research tends to blur the line between abstract concepts and their concrete manifestations 'on the ground'. This is aggravated by an insufficiently sharp distinction between theoretical and operational definitions of the concept (Sartori, 1970). Conceptual stretching can in principle be alleviated by a proper use of a ladder of abstraction or by specifying a concept with adjectives (Collier and Levitsky, 1997). In order for a concept to be valid in a higher number of cases-increasing extensionresearchers need to limit the amount of properties that identify a case as being part of that class-thus decreasing intension. To do so, a concept is often re-formulated on a higher level of abstraction, which increases the breadth of valid cases but also usually results in less discriminating power (Sartori, 2009 [1984]; Collier and Gerring, 2009). For example, a democracy is a regime that has an overarching set of properties (intension), which apply to a number of cases (extension). There exists variety in different kinds of democracy that can be identified with adjectives (Collier and Levitsky, 1997). We can subdivide democracies in parliamentary democracies and federal democracies-all of which have a specific meaning (intension) but therefore a lower number of applicable cases around the globe (extension). Once we add more cases to the concept of 'democracy' without adding extra adjectives, the concept starts to include a wider variety of divergent practices under its label, thereby stretching the general concept of 'democracy'. Alternatively, we can alleviate conceptual stretching by increasing the level of abstraction. In that case, the different kinds of democracies together form a subclass of 'national political regimes' that also includes non-democracies. In the case of polycentric urban systems the relevant adjectives are hypothesized to be the aforementioned distinctions between scales: intraurban, inter-urban and inter-regional polycentricity; and the distinction between functional and morphological polycentric urban systems.

Although most commonly used concepts in the social sciences are prone to some degree of conceptual stretching, there are a number of reasons that make polycentricity particularly susceptible to it. In urban studies, the common denominator of the concept, i.e. the definition with the least intension, denotes urban systems that consist morphologically and/or functionally of several urban cores or nuclei (Green, 2007). However, the concept has analogical meanings in biology (e.g. Goldstein, 1961) and political science (e.g. Ostrom et al., 1961), where it denotes, respectively, the multicentered character of organisms and political decision-making processes. These analogies may lead to 'spillovers': borrowing metaphors and analogies from other scientific disciplines, which are not helpful to maintain conceptual clarity. In addition, the notion of polycentric urban systems is scale-dependent. What may seem a monocentric phenomenon on one geographic scale can be part of a polycentric phenomenon on another. When a functional definition of polycentricity is hypothesized to its theoretical extremes, even the endless urban sprawl of a totally dispersed urban system is a case of 'extreme polycentricity' (Green, 2007). Therefore, whether an urban system is indeed polycentric, and what degree of polycentricity might be socially beneficial is 'in the eye of the beholder' (Lambregts, 2009). 
The notion that cities can have multiple cores plays a role in the classic works of Mumford and Geddes (cited in Green, 2007) but only started gaining theoretical momentum because of the popularity of Peter Hall's book The World Cities (1984 [1966]). In this book, Hall makes the case that multi-cored urban regions such as the Dutch Randstad or the German Ruhr Area could be functionally equivalent to large 'monocentric' cities such as Paris or New York. Although Hall's work was very influential in spatial planning circles in Europe, the oldest reference to the literal concept 'polycentricity' in the Scopus bibliographic database is Leven (1978). His contribution is part of a wider debate in urban economics over whether the monocentric Alonso-MuthMills land value model should be replaced by a polycentric version. Leven does not cite Hall, and it is unclear whether Leven used the term being aware of Hall's contribution. As we will see below, these two separate origins mirror the later distinctions in the literature between intra- and inter-urban polycentricity. Meanwhile, a third research tradition with strong normative overtones has emerged that discusses inter-regional polycentricity in the European context (Davoudi, 2003). Thus, the use of the term polycentricity in urban studies has itself polycentric scholarly roots, which might contribute to its polysemic character.

\section{Scientometrics and the sociology of science}

The academic fields of scientometrics and the sociology of science can help interpret the conceptual stretching of polycentricity. Scientometrics is concerned with quantifying knowledge and scientific developments, for example by analyzing citation patterns derived from bibliographic databases. Relatedly, the sociology of science studies the behavior of scientists and their role in society and concerns itself with questions such as 'why do scientists cite each other'?

Ever since the Institute for Scientific Information (ISI) started evaluating citation behavior in the 1960s, the resulting 'web of knowledge' revealed all sorts of regularities (e.g. Small and Griffith, 1974). Pioneer Henry Small (2003) famously calls it a map or 'landscape' of knowledge. Such a landscape of co-citations exhibits recognizable 'hills', 'valleys' and 'clusters' that can be analyzed using statistical methods. But what do these statistics mean? Does the clustering of nodes represent the interlocked groups of scientists, 'invisible colleges', that supposedly sustain academic paradigms (Crane, 1969)? And do strong connections illustrate the 'Mertonian' reputational rewards of scientific progress or the 'Kuhnian' paradigmatic rifts (Pinch, 1997 [1982])?

In reality, the act of citing has many reasons. Most importantly, people cite as part of a rhetorical strategy (Latour, 1987; Cozzens, 1989) through which they try to convince the academic audience of their point of view on a particular subject. This may include citing papers that an author disagrees with, as well as citing token references to align with 'seminal publications' in the field. But there also exists a moral economy of science in which behaving according to a citation etiquette has important reputational effects (Cronin, 1998; cf. Leydesdorff and Amsterdamska, 1990). Scientists might also cite others because of who they are and not because of what they wrote. Thus, the resulting 'map of 
knowledge' cannot be interpreted purely as a measure of 'scientific progress'. Rather, it is the sediment of cognitive development and scientific discourse as well as a reflection of a sociological process among scientists.

Leydesdorff (2001 [1998]) has shown that the network of interwoven texts that is created by a set of papers citing one another is a communication structure that shows relatively autonomous, system-level properties. The evolutionary trajectory of interlinked texts has self-organizing features: citing is not totally reducible to the (social) properties of the contributing authors, nor is any author fully capable of controlling the behavior and discourse production of the others in the same field. This implies that cognitive and intellectual development remains possible even when all involved authors cite for reputational rather than intellectual reasons. However, we can expect correlations between scientometric measures and discursive variations in (sub)fields of science because of preferential attachment of like-minded authors (cf. Barabási et al., 2002). The analysis of 'citation maps' thus consists of a combination of sociological clusters, the invisible colleges, and discursive clusters that combine to become different 'subparadigms'. Comparing the content of these different clusters can provide an adequate overview of the degree of conceptual stretching in a body of academic literature, and this is how we will approach the polycentricity concept.

\subsection{Scientometric research strategy}

To collect data on all the published scientific research that uses the concept of polycentricity, we rely on Elsevier's Scopus database. Apart from Scopus, there are two other major citation databases: Google Scholar and Web of Science. Although Google Scholar's database is extensive, preliminary analysis showed that its metadata and citation information is incomplete and inconsistent, which makes it more difficult to use for scientometric analysis. The Web of Science maintained by Thomson Reuters, for its part, has a smaller selection of journals available and is generally more US-focused (Falagas et al., 2008). Overall, Scopus has the most extensive selection of academic journals and books incorporated in its database. It also contains comprehensive citation information for articles-not books-published after 1995. Published works pre-1995 are part of Scopus' data set, but do not contain a readily accessible list of works cited (Falagas et al., 2008).

A data collection script that interfaces with Scopus' website was written in Ruby, making extensive use of the Nokogiri HTML parser library. The script queries all books and journal articles that have the word 'polycentr*'2 in either the publications' title, keywords

\footnotetext{
${ }^{2}$ The asterisk should be read as a wildcard indicating that all variations that at least begin with the letters 'polycentr' are included in the search. This means that both papers invoking the terms 'polycentricity' and 'polycentrism' are included.
} 
or abstract. In network terms, we call each of these publications a node. This first query resulted in 509 starting nodes that directly matched the search term. For each of these nodes, we then collected both the references within the publication-in network vocabulary, outgoing ties-as well as other publications that cite the specific node in question, which thus form the incoming ties. Although we started with just 509 publications, these starting nodes are directly connected to roughly 11,000 other so-called 'first-degree' nodes.

However, for a complete analysis of a citation network, it is important to also find out how these first-degree nodes are connected amongst one another. In other words, if paper A cites both book B and article C, we would also like to know whether B and C possibly cite each other. In network terms, we thus also need to collect the ties between firstdegree nodes. To do so, we collected both incoming and outgoing ties (cited by, versus references to) of all 11,000 first-degree nodes as well. Since we are only interested in whether $\mathrm{B}$ and $\mathrm{C}$ cite each other, we only retained information on ties that connect to other first-degree nodes. In this way, we constructed a complete ego-network for each of the 509 starting nodes. Merging all these networks together results in a total network of 11,000 nodes and 42,000 ties. In simple terms, the collected data now contain every publication inside of Scopus' database that either mentions, is cited by, or cites a publication that mentions the term 'polycentr's'. The entire data collection was performed in August 2012.

The earliest published work in the data set is Hobbes' Leviathan (1914 [1651]) and the most recent articles are from 2011. As pointed out earlier, because of Scopus' specific design, work published before 1995 only has incoming citations and no outgoing references. Furthermore, books do not have outgoing ties either since their contents are often not available in a digitally structured format. This means that there are two important caveats in the resulting dataset. First, the information regarding citation patterns before 1995 is partial and incomplete. Most of the pre-1995 works that are still cited today, 'the classics', are present by virtue of their current-day citations. However relations between pre-1995 works as well as 'forgotten influential contributions' that are not cited after 1995, are simply absent from the data. By the same logic, to the extent that they still contribute directly to the debate today by being cited, influential papers on closely related terms ${ }^{3}$ 'polynuclearity', 'policentricity', 'multicentricity' or 'the multiple core model' are included by virtue of their current citations. The second caveat is that the data contains a certain time lag, giving a comprehensive overview of the state of the academic debate a few years ago. Since there is considerable delay for academic publications to gain measurable influence (as it takes time for others to read new work, take notice and, most importantly, for papers that cite these new works to get published

\footnotetext{
${ }^{3}$ Synonyms for the concept from the 1990s and before.
} 
themselves), works that have been published in most recent years are at a disadvantage. The method therefore documents rather than predicts the academic debate. In the case of polycentricity in urban systems this implies, for example, that the current discussion on borrowed size and agglomeration shadows (Burger et al., 2015) in polycentric urban regions is absent. Some of the conceptual issues identified in this paper might thus already have been resolved.

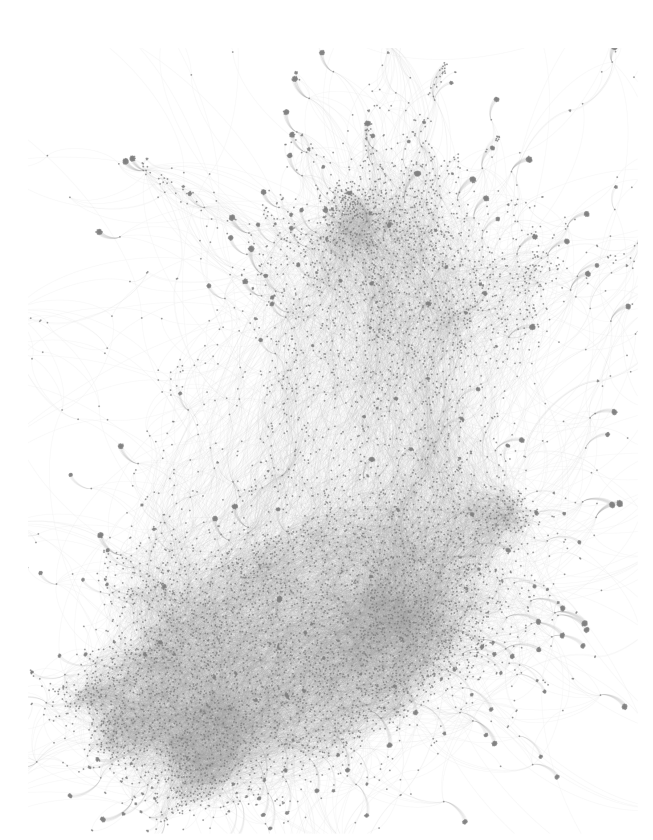

(a)

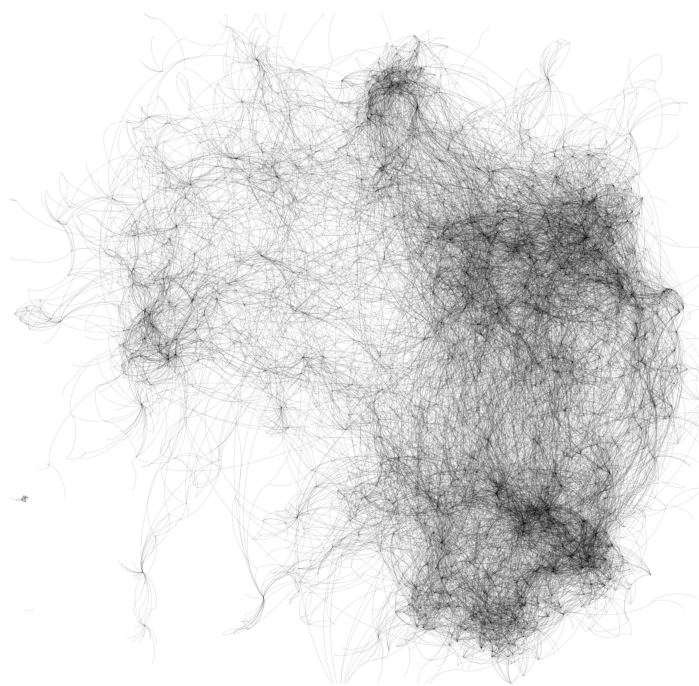

(b)

Figure 2.1 Transitory visualizations of network pruning

Figure 2.1 visualizes the resulting data as a network. In the figure, we use a force-directed visualization algorithm (Openord) in which nodes (i.e. publications) repulse each other, except when they are connected by an edge (i.e. citation), which acts as a spring. In other words, citations prevent publications from being removed too far from each other-in the same way that the force a spring exerts increases the further one tries to pull it apart. Ultimately this results in an equilibrium state in which closely connected nodes are placed spatially close to each other as well (Martin et al., 2011). However, as is clear from Figure la, using this approach on the raw data still results in an incomprehensible blob of ties and nodes without clear clusters or patterns. To circumvent this issue, we use a multi-step cleaning approach. First, all nodes with fewer than two incoming ties (i.e. cited by less than two publications in the network) are removed as they are not significant (yet) in the polycentricity debate at the moment of data collection (Figure 1b). Second, since not every publication carries equal weight in academic communities, we calculate the relative importance of each node. We do so by dividing the grand total number of cites for each publication (including those outside of the 11,000 node network) by the number of cites within the network. We then use the lower bound of Wilson's 95\% confidence interval 
(Wilson, 1927) for that score to effectively weigh each node.

$$
\text { importance }_{\text {lower }}=\frac{\left(2 c+1.96^{2}-1.96 \sqrt{1.96^{2}+4 c(n-c)}\right)}{2\left(n+1.96^{2}\right)}
$$

Where $\mathrm{c}$ is the number of cites within the network and $\mathrm{n}$ the total number of cites. This ensures that a node with 2 out of 3 , or 20 out of 30 cites, within the network does not carry the same weight as one with 200 out of 300 cites. We apply the confidence interval for two reasons. First, as confidence intervals are originally designed, we need to account for chance. If an academic work is only cited three times, the fact that two of those citations are within the network could be an effect of pure chance. Second, as an academic work gets more popular, it becomes more likely that others will cite it outside of the small group of academics that is directly engaged with a specialized topic. Hence, a relative citation rate within the network of $67 \%$ is much easier to obtain with two out of three citations than it is with 200 out of 300 total citations. These first two steps result in a smaller network of 3500 nodes and 15,000 edges. More importantly, we now also know the 'relative importance' of each node within the network, which we can use both for visualization as well as analytical purposes (see Figure 2.1b).

As indicated, based on the heterogeneous disciplinary origins of the polycentricity literature, we expect the existence of distinct academic communities that research polycentricity in different research traditions, at different scales, and in different geographical regions. Based on the literature review in the introduction, we specifically expect to discover clusters regarding the: intra-urban/inter-urban/inter-regional polycentricity and the morphological/functional polycentricity distinctions. To identify these communities, we use Louvain's modularity method (Blondel et al., 2008) to detect communities within the citation network. Much like ANOVA, modularity methods try to find communities that have a high 'modularity' or internal cohesion: a community within the overall network that has relatively strong 'internal' connections (i.e. with other community members) and relatively sparse 'external' connections (i.e. with the remainder of the network).

\subsection{Scientometric results}

Based on the pruned network, the community detection algorithm finds eight specific communities, or clusters. In Figure 2.2, each cluster is given a different color. An assessment of the works based on their title and abstract within each cluster was made to gauge whether this algorithmic, quantitative, subdivision also makes sense based on the actual content of the books and articles in each cluster. This coherence is remarkably strong, as each of the eight main clusters represents a distinct academic subfield. We indeed find the expected three scale-based central clusters that engage specifically in 
debates around polycentricity. The other five clusters can be regarded auxiliary debates, within and outside urban studies, relevant but not directly discussing polycentricity in urban studies-much in the same way as trawling for a specific fish inevitably leads to bycatch.

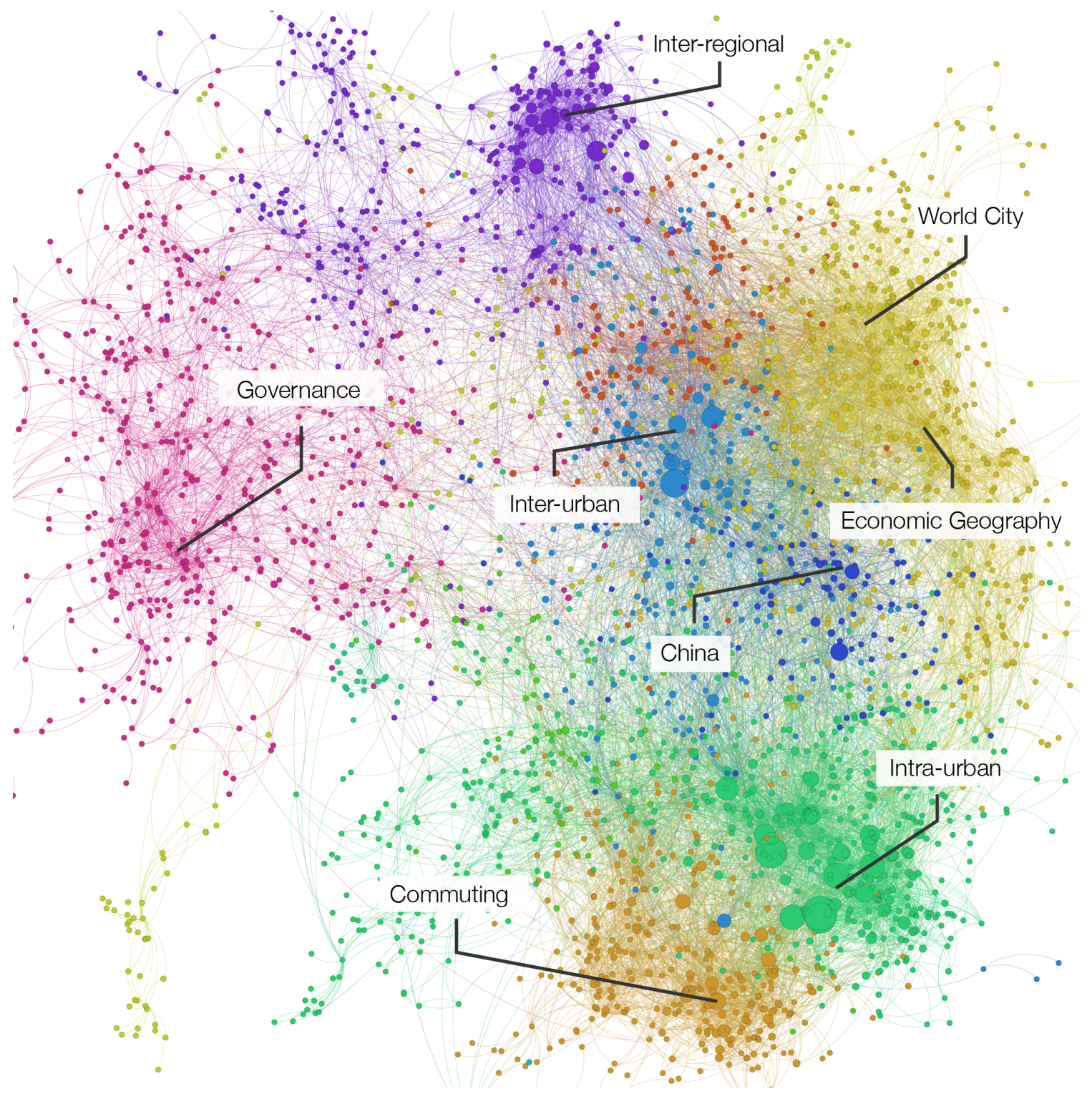

Figure 2.2 The citation network with clearly demarcated communities/clusters

Each cluster is given a name based on its topical content. Table 2.1 provides basic descriptive statistics for each cluster. It lists the number of works, the average year and the average importance score, and the standard deviation of that score for each cluster. The higher the deviation, the more the distribution of scores within the cluster is skewed (e.g. only a few core central/important works). Finally, the 'insularity'-defined as the number of citations within the cluster divided by the total number of citations within the network-and the inner-cluster density-which is calculated by dividing the number of 
citations within the cluster by the total number of possible citations and which indicates how frequent publications in each cluster tend to cite other publications in the same cluster-are provided for each cluster.

\begin{tabular}{lcccccc}
\hline Cluster & Size & $\begin{array}{c}\text { Avg. } \\
\text { year }\end{array}$ & $\begin{array}{c}\text { Avg. } \\
\text { importance }\end{array}$ & $\begin{array}{c}\text { St. Dev. } \\
\text { Avg. } \\
\text { importance }\end{array}$ & Insularity & $\begin{array}{c}\text { Inner-cluster } \\
\text { density }\end{array}$ \\
\hline Intra-urban & 365 & 1995 & 0,08 & 0,19 & 0,7 & 0,018 \\
Inter-urban & 260 & 1993 & 0,06 & 0,18 & 0,56 & 0,017 \\
Inter-regional & 360 & 1998 & 0,04 & 0,13 & 0,82 & 0,012 \\
Governance & 495 & 1995 & 0,01 & 0,03 & 0,89 & 0,007 \\
World City & 252 & 1999 & 0,03 & 0,06 & 0,65 & 0,02 \\
China & 122 & 2000 & 0,04 & 0,12 & 0,64 & 0,04 \\
Commuting & 314 & 1997 & 0,04 & 0,09 & 0,7 & 0,019 \\
Economic Geography & 386 & 1996 & 0,01 & 0,03 & 0,75 & 0,016 \\
\hline
\end{tabular}

Table 2.1 Descriptive statistics of the 6 communities within the polycentricity citation network

The modularity algorithm divides the core of the network in three distinct clusters that correspond neatly to, respectively, an intra-urban, inter-urban and inter-regional view on polycentricity. This corroborates the subdisciplinary division in the approach to polycentricity mentioned in overview articles in the literature (e.g. Davoudi, 2003). There are five additional clusters that show a strong internal coherence. First, as mentioned earlier, a distinct literature discussing 'polycentric decision-making' exists outside of urban studies in political science. We find this community in our citation network as well and label it governance. Over time, a link between this body of work and the literature on, particularly, inter-regional polycentricity within urban studies was established. That link is relatively weak and, from an urban studies perspective, the governance cluster is peripheral. This is remarkable because with 495 nodes, it is by far the largest community but exhibits a very high level of insularity (0.89) and a low average importance score (0.01) signaling the separation of political science from urban studies debates in terms of citation patterns. Second, we find a diverse collection of (urban) economic geography and regional science papers that we label economic geography. As regional economic competitiveness has been one of the main drivers of polycentricity research, it is not surprising to find a connection with that literature. The research on 'world cities' is a third cluster. The idea that a polycentric network of cities could be a substitute for a 'real monocentric world city' (Hall, 1984 [1966]) appeared very early in the con- temporary polycentricity literature (Batten, 1995; Dieleman and Faludi, 1998) and was further elaborated by Hall and Pain's influential 'The Polycentric Metropolis' (2006). The latter would probably have been far more prominent in our analysis if Scopus had included data on its references. The remaining two clusters represent the emerging research on polycentric urban systems in the Chinese context, which is currently receiving increased attention, and a cluster that consists of transport geography with a focus on commuting research. Contrary to expectations, none of the clusters expresses a clear morphological/functional polycentricity divide. 
The visualization algorithm in Figure 2.2 is the same as used in Figure 2.1. Therefore, the position of each node is based on its connections to other nodes; nodes that are close together share many connections; nodes that are spatially far apart, are also far apart in terms of shared citations and thus, most likely, far apart conceptually as well. This principle applies on the node level as well as on the cluster level, i.e. clusters that are visually close to each other have more interaction than communities that are on opposite ends of the map. Distance between published works in Figure 2.2 can therefore be thought of as a visual approximation of the cognitive distance within the communication structure of the citation network and/or of the social distance between the contributing authors. Furthermore, within communities we can distinguish large differences in clustering. For example, the 'governance' cluster is fairly spread out (which is consistent with its low inner-cluster density), while the intra-urban cluster is very concentrated (with a much higher density).

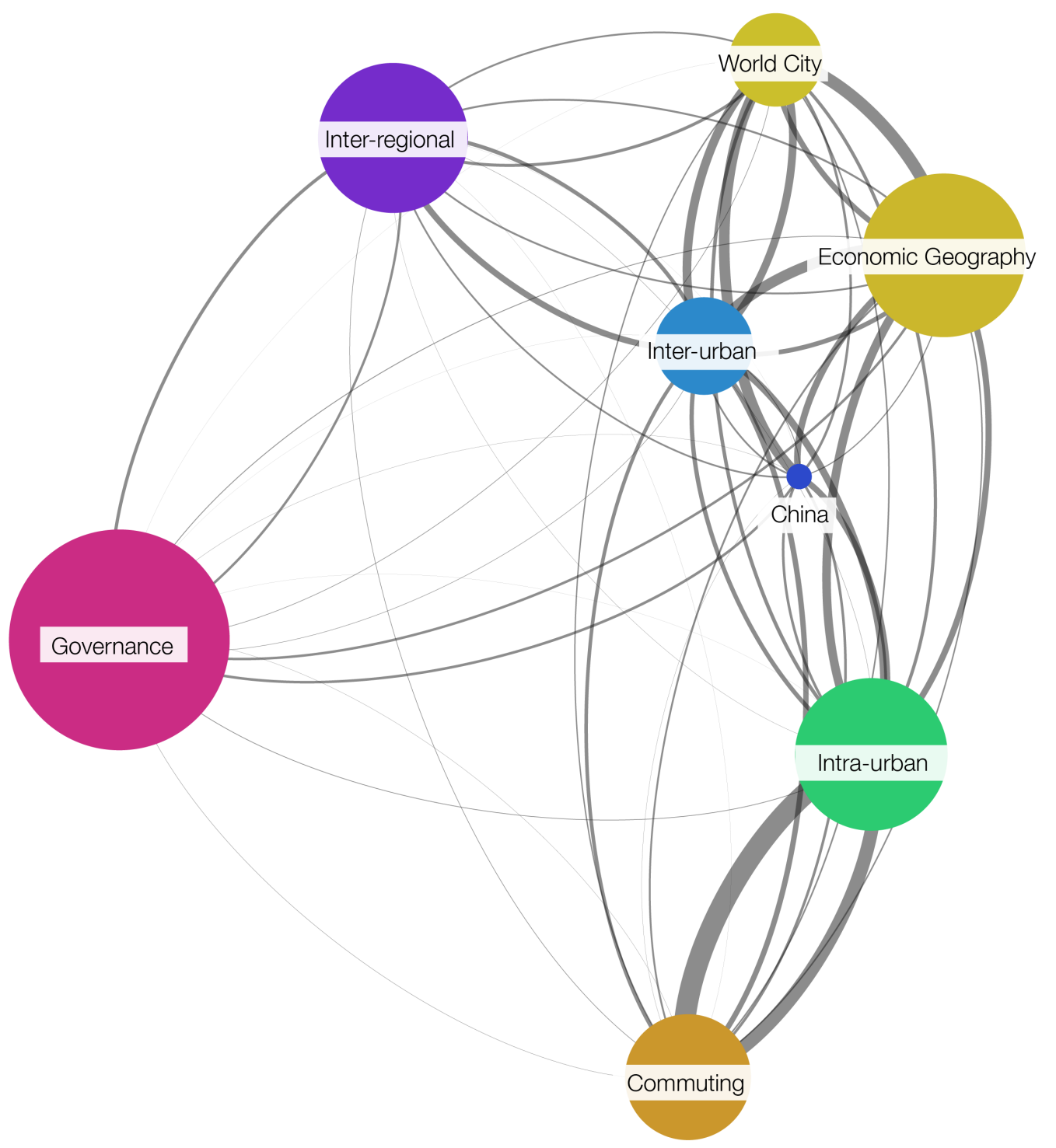

Figure 2.3 The aggregated relations between clusters 
Taking this into account, visual inspection of Figure 2.2 already signals that the concept of polycentricity is stretched. When a field has an internal coherence in the cognitive and sociological sense we would expect it to exhibit a singular central cluster around which auxiliary scientific fields are located in a star-like pattern. However, with polycentricity this is clearly not the case. In particular the intra-urban and inter-regional clusters have a very high distance from one another (with only 22 citations between them), with interurban polycentricity performing a somewhat bridging role. When we take into account that some of these scarce citations might even be 'negative' ones, used to differentiate between different conceptualizations or subfields, the fragmentation of the field only becomes more salient. We also observe that each of the three main clusters is more closely related to the five peripheral clusters than to each other. This becomes even more apparent when we study Figure 2.3. Showing the relations between the clusters in an aggregated way, it reveals that the literatures on inter-regional polycentricity and intraurban polycentricity are very far apart. In general, inter-regional polycentricity is highly insulated (i.e. $83 \%$ of all its citations are entirely within its own community) and is connected more strongly to the governance cluster literature than the other more urbanfocused communities. This is because inter-regional polycentricity concerns itself mainly with urban and regional planning rather than the analysis of polycentric urban regions (see below). And finally, we see a strong mutual interdependence between the commuting and transport and the intra-urban polycentricity clusters while the commuting and transport literature plays a far smaller role in the other polycentricity literatures. It will become apparent below that the intra-urban polycentricity cluster shares much methodological affinity with transport geography and commuting studies while this is far less the case with the other subfields. Finding a division of labor between research on the intra- and the inter-urban scale in particular is in itself not remarkable. Such a division has been foundational to the field of urban geography at least since the 1950s (Taaffe, 2005). However, it remains unclear to what extent this division has led to divergent theoretical approaches between the clusters or whether differences merely reflect diversity within each cluster. In order to answer those questions we have to investigate the contributions qualitatively.

\subsection{Qualitative content analysis of the polycentricity clusters}

Having established how papers on polycentricity are interwoven with the wider scientific discourse, this section delves into the specific differences of the definitions of polycentricity between the three main clusters (intra-urban, inter-urban and inter-regional polycentricity). We conducted a content analysis of these clusters to assess conceptual differences regarding polycentricity: how is polycentricity understood in these clusters, what methods are employed, and in which contexts is the concept applied? 'Content analysis is a research technique for making replicable and valid inferences from texts to the context of their use' (Krippendorff, 2004: 18). The associated set of procedures allows addressing issues of validity and reliability in the analysis of texts. The units and categories of analysis have to be explicated and consistently applied to allow for replication of research and intersubjective textual interpretations (Weber, 1990). The 
content analysis was based on the ten most influential publications in each clusterbased on the measure of relative importance explained above. An individual publication is the 'recording unit' that is analyzed (Weber, 1990: 21). The 10 publications are the most heavily cited within each cluster, they can be considered key publications and are assumed to be influential to and representative of the general thinking in each cluster. Each of the texts was coded twice to provide reliability through measurement stability (Krippendorff, 2004: 211-216). A first coding and analysis was conducted in March 2013 to score each of the publications on the categorical properties of: (1) the publication's research object, (2) the publication's research subject, (3) the publication's methods, and (4) the utilized data sources. Table 2.2 summarizes the provisional dominant features in each cluster regarding the four categories after the first coding round.

\begin{tabular}{|c|c|c|c|c|}
\hline Scale & Dominant object & Dominant subject & Dominant methods & $\begin{array}{l}\text { Dominant data } \\
\text { sources }\end{array}$ \\
\hline $\begin{array}{l}\text { Intra- } \\
\text { urban }\end{array}$ & $\begin{array}{l}\text { Large US metro } \\
\text { regions (Greater LA, } \\
\text { San Francisco Bay, } \\
\text { Greater Chicago) }\end{array}$ & $\begin{array}{l}\text { Urban } \\
\text { decentralization }\end{array}$ & $\begin{array}{l}\text { Spatial modeling, } \\
\text { regression analysis }\end{array}$ & $\begin{array}{l}\text { Commute, } \\
\text { employment, } \\
\text { and real estate } \\
\text { data }\end{array}$ \\
\hline $\begin{array}{l}\text { Inter- } \\
\text { urban }\end{array}$ & $\begin{array}{l}\text { Polycentric urban } \\
\text { regions' (Randstad, } \\
\text { Ruhr, Central } \\
\text { Scotland) }\end{array}$ & $\begin{array}{l}\text { Urban integration/ } \\
\text { fusion }\end{array}$ & $\begin{array}{l}\text { Conceptual papers, } \\
\text { desk research, } \\
\text { descriptive studies }\end{array}$ & $\begin{array}{l}\text { Commute data, } \\
\text { firm network } \\
\text { data, location } \\
\text { quotients }\end{array}$ \\
\hline $\begin{array}{l}\text { Inter- } \\
\text { regional }\end{array}$ & $\begin{array}{l}\text { European urban } \\
\text { structure }\end{array}$ & $\begin{array}{l}\text { Polycentricity as a } \\
\text { normative goal / } \\
\text { political } \\
\text { compromise }\end{array}$ & Discourse analysis & $\begin{array}{l}\text { Planning } \\
\text { documents, } \\
\text { literature } \\
\text { reviews }\end{array}$ \\
\hline
\end{tabular}

Table 2.2 dominant features of the three polycentricity clusters

The content analysis yields insights and the possibility of a comparison of intension and extension for the intra-urban and inter-urban cluster. Inter-regional polycentricity, as a cluster, was not coherent enough to be analyzed in the same manner. Without a single exception, most of the important publications in this cluster were found to be not about polycentricity as such, but about the discursive role of the concept in urban and regional planning on the European scale (Waterhout, 2002). Rather than discussing the empirical merits of an inter-regional polycentric system, this literature mainly concerns the 'performance' of the concept in the policy field (cf. Harrison and Hoyler, 2015). Since this diverges significantly from the empirical conceptualization of polycentricity in urban systems in the other clusters, further detailed conceptual analysis of the inter-regional cluster was subsequently set aside.

The coding procedure was repeated in December 2013. Since an alleged changing character of agglomeration economies was repeatedly mentioned in the papers across the intra- and inter-urban clusters as the driving force of the increased prominence of polycentric urban systems, the second coding round additionally investigated that issue. In addition to re-evaluating the four categories of the first coding round for the remaining two clusters, the definition and operationalization of agglomeration economies 
was explicitly examined.

Table 2.3 shows the 20 most influential publications in the intra- and inter-urban polycentricity clusters as defined by the scientometric analysis. The influential papers within the inter-urban cluster were written in a fairly short time span. Articles from special issues in Urban Studies (2001) and European Planning Studies (1998) dominate the list. The top articles in the intra-urban cluster come from a wider variety of journals and span a longer period, but here too, a select few authors contribute to several toptiered articles.

\begin{tabular}{|c|c|c|c|c|}
\hline \multirow[b]{2}{*}{ Rank } & \multicolumn{2}{|c|}{ Intra-urban polycentricity } & \multicolumn{2}{|c|}{ Inter Urban polycentricity } \\
\hline & Publication & Journal & Publication & Journal \\
\hline$\# 1$ & $\begin{array}{l}\text { Gordon and } \\
\text { Richardson } \\
\text { (1996) }\end{array}$ & $\begin{array}{l}\text { Journal of the American } \\
\text { Planning Association }\end{array}$ & $\begin{array}{l}\text { Dieleman and } \\
\text { Faludi (1998) }\end{array}$ & $\begin{array}{l}\text { European } \\
\text { Planning Studies }\end{array}$ \\
\hline \#2 & $\begin{array}{l}\text { Cervero and Wu } \\
\text { (1997) }\end{array}$ & $\begin{array}{l}\text { Environment and } \\
\text { Planning } \mathrm{A}\end{array}$ & $\begin{array}{l}\text { Kloosterman and } \\
\text { Musterd (2001) }\end{array}$ & Urban Studies \\
\hline \#3 & $\begin{array}{l}\text { Giuliano and } \\
\text { Small (1991) }\end{array}$ & $\begin{array}{l}\text { Regional Science and } \\
\text { Urban Economics }\end{array}$ & Davoudi (2003) & $\begin{array}{l}\text { European } \\
\text { Planning Studies }\end{array}$ \\
\hline$\# 4$ & $\begin{array}{l}\text { Gordon et al., } \\
\text { (1986) }\end{array}$ & $\begin{array}{l}\text { Environment and } \\
\text { Planning A }\end{array}$ & Batten (1995) & Urban Studies \\
\hline \#5 & $\begin{array}{l}\text { McDonald and } \\
\text { Prather (1994) }\end{array}$ & Urban Studies & Parr (2004) & Regional Studies \\
\hline$\# 6$ & $\begin{array}{l}\text { Small and Song } \\
(1994)\end{array}$ & $\begin{array}{l}\text { Journal of Urban } \\
\text { Economics }\end{array}$ & Champion (2001) & Urban Studies \\
\hline$\# 7$ & $\begin{array}{l}\text { McMillen and } \\
\text { McDonald (1998) }\end{array}$ & $\begin{array}{l}\text { Journal of Urban } \\
\text { Economics }\end{array}$ & $\begin{array}{l}\text { Van der Laan } \\
(1998)\end{array}$ & Regional Studies \\
\hline \#8 & Garreau (1991) & Book & $\begin{array}{l}\text { Bailey and Turok } \\
\text { (2001) }\end{array}$ & Urban Studies \\
\hline$\# 9$ & $\begin{array}{l}\text { Berry and Kim } \\
(1993)\end{array}$ & Geographical Analysis & Albrechts (1998) & $\begin{array}{l}\text { European } \\
\text { Planning Studies }\end{array}$ \\
\hline$\# 10$ & Anas et al (1998) & $\begin{array}{l}\text { Journal of Economic } \\
\text { Literature }\end{array}$ & $\begin{array}{l}\text { Kloosterman and } \\
\text { Lambregts (2001) }\end{array}$ & Urban Studies \\
\hline
\end{tabular}

Table 2.3 The 10 most influential papers in the intra- and inter-urban polycentricity clusters

When we examine the extension - the breadth of situations that a concept applies to-of the polycentricity concept in the most influential publications, two remarkable patterns emerge. First, influential texts in intra-urban polycentricity are all case studies of US metropolitan areas: Greater Los Angeles (Gordon et al., 1986; Giuliano and Small, 1991; Small and Song, 1994; Gordon and Richardson, 1996), San Francisco (Cervero and Wu, 1997) and Chicago (McDonald and Prather, 1994; McMillen and McDonald, 1998). In comparison, the inter-urban literature almost exclusively ${ }^{4}$ features case studies from

\footnotetext{
${ }^{4}$ The only exception is Batten (1995) that compares the Randstad with Japan's Kansai region.
} 
northwestern Europe: the Dutch Randstad dominates (Batten, 1995; van der Laan, 1998; Kloosterman and Lambregts, 2001), but also the Flemish Diamond (Albrechts, 1998) and Central Scotland (Bailey and Turok, 2001) are examined. The remaining papers in both clusters are of a more conceptual nature, but stick to the geographical context of the rest of their respective cluster. Based on this observation, it seems that conceptually dividing the literature in a classification of 'intra-urban' and 'inter-urban' scale is somewhat misleading. The studies on the US context that we labeled, following the literature, intraurban' tend to be about bigger populations spread over equal or larger areas than the European cases that we designated, again following the literature, as inter-urban'. However the content analysis indicates that, instead of subdividing these studies in terms of scale, a better interpretation of the differences between the clusters would be to distinguish between geographic contexts. The distinction of Champion (2001) between polycentric regions emerging from urban decentralization and polycentric urban regions emerging from urban integration or fusion seems more apt. Cases in both the US and EU contexts are becoming more polycentric because of the upscaling of daily urban systems and changes in how agglomeration economies function, but do so in a radically different historical context, giving rise to processes that seem more divergent than they actually are (Clark and Kuijpers-Linde, 1994; Clark, 2000).

A second pattern of difference in the extension of the concept between the two clusters pertains to the question of what are viable cases of a polycentric region. In the inter-urban cluster, following Hall (1984 [1966]), the Polycentric Urban Region (PUR) is regarded a discrete type of actually existing urban region (Parr, 2004). Some papers (e.g. Kloosterman and Musterd, 2001; Parr, 2004) subsequently engage in the endeavor of classifying existing regions in either the monocentric or polycentric type. On the other hand, without exception, the intra-urban polycentricity cluster, following Leven (1978) and the urban economics tradition based on the Alonso-Muth-Mills framework (Clark, 2000), discusses the polycentric versus the monocentric model of a city. The discussion is about which model has a better fit with reality in terms of explained variance (Clark, 2000). Not a single author assumes that this model actually exists in its pure form-with the possible exception of Garreau's Edge City (1991), which is geared more to a nonacademic audience. From this perspective held in the intra-urban cluster, the debate within the inter-urban cluster on whether a region is sufficiently polycentric to be categorized as such is moot. The point here is not whether a region is polycentric, but rather how regions are becoming more polycentric. Such a misunderstanding between those looking at abstract models of reality versus 'actually existing' urban forms occurs often when theory travels between the methodological and empirical disciplines of regional science and human geography (cf. Mäki, 2004, for a comparable discussion regarding von Thünen's Isolierte Staat, 1966 [1824]). Therefore, the difference in extension between the intra-urban and the inter-urban cluster is not so much based on scale, but on social context, method, and applicability. In Collier and Levitsky's (1997) terms: the inter-urban cluster's attempts to alleviate conceptual stretching involved decreasing the extension, by making the theory only applicable to a particular kind of region. On the other hand, in the intra-urban cluster, polycentricity exists at a higher level of abstraction by specifying it in terms of an abstract model. 


\section{Differences in intension between the intra- and inter-urban clusters}

When we compare the intension-the properties ascribed to a concept that 'do' the theoretical work-of polycentricity in the intra-urban and inter-urban clusters, the positions taken in individual papers do not conform neatly to the boundaries of the clusters these papers are in. While we did not find remarkable within-cluster variations regarding the extension of the concept, the contrary is the case with the intension. There is a widely-held consensus across the two clusters that a new form of urbanization gradually became dominant in the second half of the 20th century, of which the spatial outcomes diverge from the classic model of the monocentric city. Some of the authors emphasize near-universal car ownership as fundamental to this change (Gordon and Richardson, 1996), others emphasize demographic factors (Champion, 2001). However, in a nearly univocal chant among the 20 articles, the changing pattern of urbanization is attributed to fundamental changes in how the spatial economy works. Although some authors mention terms such as 'post- industrial' (Albrechts, 1998), 'post-modern' (Berry and Kim, 1993) or 'post-Fordism' (Kloosterman and Musterd, 2001) to typify this new economic regime, an overarching consensus on the theoretical implications of such terms is absent. Nevertheless, all authors tend to agree that the change in urban structure is related to a parallel qualitative and/or quantitative change in how agglomeration economies function (Anas et al., 1998). Therefore, in the literature surveyed for the content analysis, discussion on the appearance of polycentricity in urban systems unequivocally disguises a debate on changes in agglomeration economies. 'Agglomeration economies', however, is a slippery concept in itself that encompasses a variety of external economies of scale emerging from socio-spatial processes that operate on different geographical scales (Rosenthal and Strange, 2003). Different definitions of agglomeration economies in each of the 20 papers therefore play an important role in explaining different assessments of polycentricity in urban systems.

Rosenthal and Strange (2003) define three different kinds of agglomeration economy effects, i.e. labor market pooling, information spillovers between firms and shared inputs. In a polycentric urban system, size can be shared between cities (Alonso, 1973; Burger et al., 2015) in order to reach certain threshold values for each of these three mechanisms leading to increased competitiveness. Of course, these three mechanisms have different threshold values and therefore they each refer to different (potential) geographies of polycentric urban systems. Hence, in the second round of coding, we assessed how agglomeration economies supposedly generate increased polycentricity of the urban system. Furthermore, by examining the methods utilized, we can infer how agglomeration economies are implicitly operationalized. We classify these by using Rosenthal and Strange's (2003) elaboration of Alfred Marshall's (1920 [1890]) threefold taxonomy of agglomeration economies.

Logically, given that commuting data is often available for urban regions, the labor market effects have been central to research on polycentric urban systems. Increased labor market pooling is positively associated with thicker travel-to-work areas (Melo and Graham, 2014). Therefore, an increase in geographic scope of the travel-to-work area 
through commuting is indicative of a greater potential for labor market pooling. Out of the 20 papers studied in depth, 11 feature an empirical analysis; and only four of those 11 (McDonald and Prather, 1994; Small and Song, 1994; Gordon and Richardson, 1996; Kloosterman and Lambregts, 2001) do not take commuting patterns or effects as a basic building block of their empirical research. Commuting analyses imply the definition of a functional urban region, and this is emblematic of the lack of morphological studies in this sample of highly influential papers. Only Gordon and Richardson (1996) and McDonald and Prather (1994) and arguably Small and Song (1994) are morphological rather than functional studies.

Apart from labor market pooling, the other two agglomeration economy effects defined by Rosenthal and Strange (2003) are also acknowledged in the 20 papers examined here. Several authors (Garreau, 1991; Giuliano and Small, 1991; Batten, 1995; Albrechts, 1998; Dieleman and Faludi, 1998; McMillen and McDonald, 1998; Bailey and Turok, 2001; Champion, 2001; Kloosterman and Lambregts, 2001; Kloosterman and Musterd, 2001; Davoudi, 2003; Parr, 2004) note that sharing inputs is a relevant mechanism of agglomeration economies. Sharing inputs results in specialization, affects the regional spatial division of labor and increases complementarity between locations. Interestingly enough, information spillovers were less emphasized than initially expected, but were still considered to be worth mentioning in quite a few studies (by Giuliano and Small, 1991; Cervero and Wu, 1997; Anas et al., 1998; McMillen and McDonald, 1998; van der Laan, 1998; Kloosterman and Lambregts, 2001; Kloosterman and Musterd, 2001; Parr, 2004).

Although all three types of agglomeration economies are widely acknowledged as driving forces in the polycentricity literature, the question remains to what extent they influence each other. Can we aggregate these descriptions of different external economies of scale across papers into a coherent spatially homological narrative of a region becoming more polycentric? How do papers deal with the interaction between the various agglomeration economy effects? Do well-integrated labor markets attract firms that subsequently appear agglomerated? Or, inversely, do agglomerated firms induce migration of workers? An intermediate solution would be to specify some kind of co-evolutionary process between household and industry location determining the functioning of the urban system (Clark and Kuijpers-Linde, 1994). These questions regarding causality seem to be pivotal to understand what kind(s) of polycentricity might enhance competiveness. In the USbased ('intra-urban') cluster, papers are making both the case for a 'household location determines industry location' mechanism (Garreau, 1991; Small and Song, 1994), and, somewhat more implicitly, the opposite (Gordon and Richardson, 1996). The European inter-urban cluster exhibits consensus regarding the co-evolution between the two processes (Albrechts, 1998; van der Laan, 1998; Champion, 2001; Kloosterman and Musterd, 2001), although such a position is neither completely absent from the US literature (Anas et al., 1998; McMillen and McDonald, 1998). This variety of positions on causality across the clusters exemplifies that the intension of polycentricity is contested within the clusters as well as between them, despite the intra-urban cluster having a more parsimonious shared theoretical apparatus owing to its modeling methodology. 
Apart from the differences on causality, there seems to be agreement across some papers that different types of agglomeration economies play out on different scales (McMillen and McDonald, 1998; van der Laan, 1998), as well as that different (sub)populations, in particular based on educational attainment, show different scalar effects (Cervero and $\mathrm{Wu}, 1$ 1997; Kloosterman and Lambregts, 2001). This implies that a polycentric region in the singular based on the idea of a coterminous geography of several different agglomerative processes is nowhere explicitly argued for in the literature: labor markets, shared inputs and information spillovers all work on a different geographical scale (cf. van Meeteren, 2013; Burger et al., 2014b). Nevertheless, apart from van der Laan (1998), the regions do tend to be defined in the singular and thus implicitly adopt that very frame of coterminous agglomeration economies. The influential papers in this sample do not yet assess the multiplexity of effects influencing urban system formation that have more recently become central in the academic debate (Burger et al., 2014a, 2014b).

\subsection{Conclusion}

Before we draw some final conclusions on the extent to which conceptual stretching has hampered urban polycentricity research and propose some suggestions to prevent that in the future, we would like to reflect briefly on the methods employed in this paper. This study shows that an informed quantitative scientometric study of a specific research domain can yield qualitative meaningful results. The quantitative 'mapping' of a citation network-effectively creating a bird's eye view of a body of literature-and the subsequent qualitative assessment of key works could be extended to other academic discussions or communities. Apart from being an efficient way to identify key works or acquaint oneself with a new literature in an efficient manner, such a 'literature review from above' can be useful to assess the alleged versus the real paradigmatic differences in scientific debates from a somewhat more distant standpoint, than is the case if one describes a literature from 'within' a position in the network.

That such an approach can indeed challenge some taken-for-granted aspects within a certain field is apparent from our analysis of the polycentricity debate in urban studies. A priori, we identified two major axes of debate around which the stretching of polycentricity is alleged to revolve: a discussion on functional versus morphological polycentricity and a discussion on scale. However, our analysis shows that neither are pivotal causes of conceptual stretching. Morphological empirical analyses of polycentric regions are conspicuously absent among influential papers. Furthermore, the alleged scale difference between different strands of the urban polycentricity literature appears not related to geographical scale but to different methods and empirical contexts. Instead, we reasoned that the ambiguity around the geographic impact of different kinds of agglomeration economies and implicit questions regarding the direction of causality between these kinds are a more important cause of the 'confusion of tongues' within the polycentricity debate.

In order to rectify this conceptual confusion, we have to re-conceptualize the stretched 
concept of polycentricity. According to Sartori (2009 [1984]: 126), a useful approach to this end is to separate the defining, or necessary, properties from the accompanying, contingent, properties of a concept, and then re-assess how many different concepts we need to categorize all the empirical objects we want to make statements about, for example by assigning adjectives (Collier and Levitsky, 1997). We have seen that the intraurban cluster defined polycentricity on a higher level of abstraction than the inter-urban cluster. Although this can potentially resolve the extension problem-all cases of urban systems are up for consideration-we nevertheless lose some discriminating power as regards the context-sensitivity of the theory. This shows that strategies to achieve clarity are theory-dependent.

Another possibility would be specifying the theory differently by critically re-evaluating the adjectives. With regard to the intension of polycentricity, we conclude that the conceptual stretching ultimately relates to an undue focus on fixed geographical scales. Nearly all authors of the influential papers studied herein have implicitly tended to assume that agglomeration effects were spatially coterminous when studying urban regions. There are two ways out of this false assumption, both of which are already explored in recent work (Burger et al., 2014a, 2014b). Either we discuss one type of agglomeration economies at a time, such as labor market pooling or shared inputs, and then compare the spatial structure of urbanized regions of roughly equal size and population to assess the degree of polycentricity. Alternatively, we can compare the spatial reach of different kinds of agglomeration economies while acknowledging that each spatial object will have a different geometry, making comparisons of geographical entities more complicated. Urban geographers might prefer the first approach that focuses on the specific urban region while economic geographers and regional economists might prefer the second approach that studies a particular spatial-economic mechanism. Nevertheless, whatever approach one prefers, we caution researchers against conflating their empirical results with theoretical treatises of the other variety, as doing so will only reinforce the Babylonian confusion that has hampered the academic discussion on polycentricity. 


\section{References}

Albrechts L (1998) The Flemish Diamond: Precious gem and virgin area. European Planning Studies 6(4): 411-424.

Alonso W (1973) Urban zero population growth. Daedalus 102(4): 191-206.

Anas A, Arnott R and Small KA (1998) Urban spatial structure. Journal of Economic Literature 36(3): 1426-1464.

Bailey N and Turok I (2001) Central Scotland as a polycentric urban region: Useful planning concept or chimera? Urban Studies 38(4): 697-715.

Barabási AL, Jeong H, Néda Z, Ravasz E, Schubert A and Vicsek T (2002) Evolution of the social network of scientific collaborations. Physica A: Statistical Mechanics and Its Applications 311(3-4): 590-614.

Batten DF (1995) Network cities: Creative urban agglomerations for the 21st century. Urban Studies 32(2): 313-327.

Batty M (2001) Polynucleated urban landscapes. Urban Studies 38(4): 635-655.

Berry BJL and Kim H-M (1993) Challenges to the monocentric model. Geographical Analysis 25(1): 1-4.

Blondel VD, Guillaume J, Lambiotte R and Lefebvre, E (2008) Fast unfolding of communities in large networks. Journal of Statistical Mechanics: Theory and Experiment 2008 P 100108.

Burger MJ and Meijers EJ (2012) Form follows function? Linking morphological and functional polycentricity. Urban Studies 49(5): 1127-1149.

Burger MJ, Meijers EJ and van Oort FG (2014a) Multiple perspectives on functional coherence: Heterogeneity and multiplexity in the Randstad. Tijdschrift voor Economische en Sociale Geografie 105(4): 444-464.

Burger MJ, van der Knaap B and Wall RS (2014b) Polycentricity and the multiplexity of urban networks. European Planning Studies 22(4): 816-840.

Burger MJ, Meijers EJ, Hoogerbrugge MM and Tresserra JM (2015) Borrowed size, agglomeration shadows and cultural amenities in North-West Europe. European Planning Studies 23(6): 1090-1109.

Cattan N (ed.) (2007) Cities and Networks in Europe. A Critical Approach to Polycentrism. Esher: John Libbey Eurotext. 
CEC (2011) Territorial Agenda 2020 - Towards an Inclusive, Smart and Sustainable Europe of Diverse Regions. Luxembourg: Office for Official Publications of the European Communities.

Cervero R and Wu K-L (1997) Polycentrism, commuting, and residential location in the San Francisco Bay area. Environment and Planning A 29(5): 865-886.

Champion A (2001) A changing demographic regime and evolving polycentric urban regions: Consequences for the size, composition and distribution of city populations. Urban Studies 38(4): 657-677.

Clark WAV (2000) Monocentric to policentric: New urban forms and old paradigms. In: Bridge $\mathrm{G}$ and Watson S (eds) A Companion to the City. Malden/Oxford: Blackwell Publishing, 141-155.

Clark WAV and Kuijpers-Linde M (1994) Commuting in restructuring urban regions. Urban Studies 31(3): 465-483.

Collier D and Gerring J (eds) (2009) Concepts and Method in Social Science. London/New York: Routledge.

Collier D and Levitsky S (1997) Democracy with adjectives: Conceptual innovation in comparative research. World Politics 49(3): 430-451.

Cozzens SE (1989) What do citations count? The rhetoric-first model. Scientometrics 15(5): 437-447.

Crane D (1969) Social structure in a group of scientists: A test of the 'invisible college' hypothesis. American Sociological Review 34(3): 335-352.

Cronin B (1998) Metatheorizing citation. Scientometrics 43(1): 45-55.

Davoudi S (2003) Polycentricity in European spatial planning: From an analytical tool to a normative agenda. European Planning Studies 11(8): 979-999.

Davoudi S (2007) Polycentricity: Panacea or pipedream? In: Cattan N (ed.) Cities and Networks in Europe: A Critical Approach of Polycentrism. Esher: John Libbey Eurotext, 65-75.

Dieleman FM and Faludi A (1998) Polynucleated metropolitan regions in Northwest Europe: Theme of the special issue. European Planning Studies 6(4): 365-377.

Falagas ME, Pitsouni EI, Malietzis GA and Pappas G (2008) Comparison of PubMed, Scopus, Web of Science, and Google Scholar: Strengths and weaknesses. The FASEB Journal 22(2): 338-342.

Garreau J (1991) Edge City. New York: Doubleday. 
Giuliano G and Small KA (1991) Subcenters in the Los Angeles region. Regional Science and Urban Economics 21(2): 163-182.

Goldstein S (1961) Studies of two polycentric chytrids in pure culture. American Journal of Botany 48(4): 294-298.

Gordon P and Richardson HW (1996) Beyond polycentricity: The dispersed metropolis, Los Angeles, 1970-1990. Journal of the American Planning Association 62(3): 289295.

Gordon P, Richardson HW and Wong HL (1986) The distribution of population and employment in a polycentric city: The case of Los Angeles. Environment and Planning A 18(2): 161-173.

Green N (2007) Functional polycentricity: A formal definition in terms of social network analysis. Urban Studies 44(11): 2077-2103.

Hall P (1984 [1966]) The World Cities. London: George Weidenfeld \& Nicolson Limited.

Hall P and Pain K (eds) (2006) The Polycentric Metropolis. London: Earthscan.

Harrison J and Hoyler M (eds) (2015) Megaregions, Globalization's New Urban Form. Cheltenham: Edward Elgar.

Hobbes T (1914 [1651]) Leviathan. London: J.M. Dent \& Sons Limited.

Kloosterman RC and Lambregts B (2001) Clustering of economic activities in polycentric urban regions: The case of the Randstad. Urban Studies 38(4): 717-732.

Kloosterman RC and Musterd S (2001) The polycentric urban region: Towards a research agenda. Urban Studies 38(4): 623-633.

Krippendorff K (2004) Content Analysis. An Introduction to its Methodology (2nd edn). London/Thousand Oaks, CA/New Delhi: Sage.

Lambregts B (2009) The Polycentric Metropolis Unpacked. PhD Thesis: University of Amsterdam.

Latour B (1987) Science in Action. How to Follow Scientists and Engineers through Society. Cambridge, MA: Harvard University Press.

Leven CL (1978) Growth and nongrowth in metropolitan areas and the emergence of polycentric metropolitan form. Papers in Regional Science 41(1): 101-112.

Leydesdorff L (2001 [1998]) The Challenge of Scientometrics. Boca Raton, FL: Universal Publishers. 
Leydesdorff L and Amsterdamska O (1990) Dimensions of citation analysis. Science, Technology, \& Human Values 15(3): 305-335.

McDonald JF and Prather PJ (1994) Suburban employment centres: The case of Chicago. Urban Studies 31(2): 201-218.

McMillen DP and McDonald JF (1998) Suburban subcenters and employment density in metropolitan Chicago. Journal of Urban Economics 43(2): 157-180.

Mäki U (2004) Realism and the nature of theory: A lesson from JH von Thünen for economists and geographers. Environment and Planning A 36(10): 1719-1736.

Markusen A (1999) Fuzzy concepts, scanty evidence, policy distance: The case for rigour and policy relevance in critical regional studies. Regional Studies 33(9): 869-884.

Marshall A (1920 [1880]) Principles of Economics. London: Macmillan and Co.

Martin S, Brown M, Klavans R and Boyack KW (2011) OpenOrd: An open-source toolbox for large graph layout. Proceedings SPIE 7868, Visualization and Data Analysis 2011.

Melo PC and Graham DJ (2014) Testing for labour pooling as a source of agglomeration economies: Evidence for labour markets in England and Wales. Papers in Regional Science 93(1): 31-52.

Ostrom V, Tiebout CM and Warren R (1961) The organization of government in metropolitan areas: A theoretical inquiry. The American Political Science Review 55(4): 831-842.

Parr JB (2004) The polycentric urban region: A closer inspection. Regional Studies 38(3): 231-240.

Pinch TJ (1997 [1982]) Kuhn - The conservative and radical interpretations: Are some Mertonians Kuhnians' and some Kuhnians Mertonians'? Social Studies of Science 27(3): 465-482.

Rosenthal SS and Strange WC (2003) Geography, industrial organization, and agglomeration. Review of Economics and Statistics 85(2): 377-393.

Sartori G (1970) Concept misformation in comparative politics. American Political Science Review 64(4): 1033-1053.

Sartori G (2009 [1975]) The Tower of Babel. In: Collier D and Gerring J (eds) Concepts and Method in Social Science. New York/London: Routledge, 61-97.

Sartori G (2009 [1984]) Guidelines for concept analysis. In: Collier D and Gerring J (eds) Concepts and Method in Social Science. New York/London: Routledge, 97-151. 
Small HG (2003) Paradigms, citations, and maps of science: A personal history. Journal of the American Society for Information Science and Technology 54(5): 394-399.

Small HG and Griffith BC (1974) The structure of scientific literatures I: Identifying and graphing specialties. Science Studies 4(1): 17-40.

Small KA and Song S (1994) Population and employment densities: Structure and change. Journal of Urban Economics 36(3): 292-313.

Taaffe EJ (2005) Some thoughts on the development of urban geography in the United States during the 1950s and 1960s. In: Berry BJL and Wheeler JO (eds) Urban Geography in America, 1950-2000. New York/London: Routledge, 49-60.

Vandermotten C, Halbert L, Roelandts M and Cornut P (2008) European planning and the polycentric consensus: Wishful thinking? Regional Studies 42(8): 1205-1217.

Van der Laan L (1998) Changing urban systems: An empirical analysis at two spatial levels. Regional Studies 32(3): 235-247.

Van Meeteren M (2013) The role of agglomeration economies for SME transnationalization: Bypassing the global urban service nexus? In: Tamásy $\mathrm{C}$ and Revilla Diez J (eds) Regional Resilience, Economy and Society. Farnham: Ashgate, 231-251.

Vasanen A (2012) Functional polycentricity: Examining metropolitan spatial structure through the connectivity of urban subcentres. Urban Studies 49(16): 3627-3644.

Von Thünen JH (1966 [1826]) Von Thünen's Isolated State. Oxford: Pergamon Press.

Waterhout B (2002) Polycentric development, what is behind it? In: Faludi A (ed.) European Spatial Planning. Cambridge, MA: Lincoln Institute of Land Policy, 83103.

Weber RP (1990) Basic Content Analysis. Beverly Hills, CA: Sage.

Wilson EB (1927) Probable inference, the law of succession, and statistical inference. Journal of the American Statistical Association 22(158): 209-212. 